\title{
Perspectives from those involved in Healthy Stadia
}

\author{
Daniel Cade ${ }^{1}$,, Kathryn Curran²., Andy Fuller ${ }^{3}$., Jenny Hacker ${ }^{4}$., Clive
}

Knight ${ }^{5}$., Simon Lansley 6 ., Daniel Parnell ${ }^{7}$., Matthew Philpott ${ }^{8}$.

${ }^{1}$ Schwery Consulting, Güterstrasse 13, 2502 Biel/Bienne, Switzerland. Email: daniel.cade@schwery.com

${ }^{2}$ Centre for Active Lifestyles, Carnegie Faculty, Leeds Beckett University, Leeds, LS6 3QS, UK. Email: K.M.Curran@leedsbeckett.ac.uk

${ }^{3}$ Independent Researcher, Reading Sideways, 2312 VM, The Netherlands. Email:

sideways.editor@gmail.com

${ }^{4}$ Independent Public Health Consultant, Inspire Research, Training and Consultancy. Email: jenny.hacker@inspiraepublichealth.co.uk

${ }^{5}$ Owestry Team Tennis, Dudleston Grange, Dudleston Heath, Nr Ellesmere, Shropshire, United Kingdom.Email: clive.knight182@hotmail.co.uk

${ }^{6}$ Connect Sport Ltd, UK. Email: simonlansley@ connectsport.co.uk

${ }^{7}$ Business School, Manchester Metropolitan University, Manchester, United Kingdom.

${ }^{8}$ European Healthy Stadia Network CiC, Liverpool, UK. Email:

matthew.philpott@healthystadia.eu

Corresponding author:

Dr Daniel Parnell

Business School

Manchester Metropolitan University

United Kingdom

M15 6BH

Email: D.Parnell@mmu.ac.uk 


\title{
Perspectives from those involved in Healthy Stadia
}

\author{
Healthy stadia is a growing agenda across industry and in turn academia. In this \\ era of growth much of the research literature is primarily sourced from academics \\ with little contribution from applied and industry stakeholders. As such, the \\ editors have sought to offer practitioners a platform to share novel projects, \\ perspectives and preliminary intervention evaluation findings. This applied \\ article intends to share evaluation and insight from applied practice, to encourage \\ closer debate between the academic community and applied industry.
}

Keywords: Healthy Stadia, Public Health, Stadia

\section{Introduction}

Sport stadia and sport oriented community based interventions have been highlighted as vehicles to promote public health (Drygas et al 2013; Bangsbo, Krustrup and Dvorak 2014; Curran et al 2014; Hunt et al 2014; Parnell and Richardson 2014; Parnell et al 2015; Parnell and Pringle, 2016). There is growing recognition of the role that amateur and professional sport clubs can play in improving public health outcomes across local communities, including those who interact with stadia and sport venues (Drygas et al 2013; Martin et al 2016). Indeed, it was the research of Drygas et al. (2013) that helped cement the European Healthy Stadia Network, which works with sports clubs, stadia operators and governing bodies of sport to develop stadia as health promoting environments. The European Healthy Stadia Network offers assistance through one-toone support, guidance documents, case studies of good practice, benchmarking tools and research (Martin et al 2016).

The purpose of this special issue is to disseminate a range of contributions from practitioners, commissioners and researchers involved in, or concerned with, the healthy stadia agenda. The editors [Parnell, Curran and Philpott] hope that by developing a 
platform for dissemination, it will enable those working on, and around, the healthy stadia agenda to share novel projects, stories, perspectives and insight. This applied article intends to encourage a closer debate between the academic community and applied industry. In no particular order, we are pleased to highlight the work of Ms Jenny Hacker, discussing a stadium based approach to men's health through Albion in the Community (AITC) at Brighton Hove Albion Football Club, Dr Andy Fuller on his experiences of football and health promotion in the Netherlands, Mr Clive Knight of Owestry Team Tennis on his experiences making community stadia accessible to the local community, Mr Simon Lansley of ConnectSport on his personal experiences on sharing the community sport message on social media, and Mr Dan Cade from Schwery Consulting on sustainable sponsorship.

Our first contributor is Ms Jenny Hacker, is an independent public health consultant who has previously led a number of health promoting programmes at Albion in the Community, the charitable arm of Brighton and Hove Albion Football Club (England). In her contribution, Jenny discusses the Shape Up at the Stadium project offering both insights and preliminary evaluation findings.

\section{Shape Up at the Stadium, Albion in the Community}

Shape Up at the Stadium is a weight management programme for men delivered at the Amex, home of Brighton and Hove Albion Football Club. Targeting men with a body mass index (BMI) of $25-43 \mathrm{~kg} / \mathrm{m}^{2}$, it is a self-referral programme for men wanting to lose weight in a supportive group environment, delivered by staff from the club's charitable arm, Albion in the Community (AITC).

Each programme lasts for ten weeks. Sessions include nutritional advice, behaviour change strategies and physical activity sessions. The programme forms part 
of a broader collection of Shape Up projects delivered as part of the Tier two community based weight management service, funded by Brighton and Hove Public Health. Additional Shape Up programmes are delivered in the city centre or community venues and include a programme for new mothers.

As part of the evaluation of the Shape Up programme participants are weighed and measured at the start of the programme (week 1), and weighed again at the midpoint (week 5) and end of the programme (week 10). Responses to questions on behaviour were recorded at the start and end of each ten-week programme. The primary outcomes of the programmes include a $2 \%$ reduction in body weight at week ten, reductions in waist circumference, increases in physical activity levels, and changes to diet, specifically increased consumption of fruit and vegetables and reduced consumption of food high in fats, sugars.

Analysis of available data shows that the programme delivered at the stadium has been the most successful of the wider local Shape Up programmes and supported many men to kick start healthier lifestyles. Data was available from 45 men. The vast majority (97\%) attended more than half of the sessions. In terms of weight loss, more than a third (36\%) achieved the target of $2 \%$ or greater weight loss by the end of the ten-week programme. This was more than twice the average of $15 \%$ achieved over the overall Shape Up programme. This supports a settings based approach to promoting health (Martin et al., 2016; Parnell et al., 2014).

The overall weight reduction for the group was a loss of $84.75 \mathrm{~kg}$. One participant managed to increase his weight slightly, whilst $29 \%$ experienced no change. However, $69 \%$ of men lost weight over the ten weeks, which ranged from 0.3 to $7.9 \mathrm{~kg}$. The majority of men, $67 \%$, also achieved reductions to their waist circumference, 
ranging from $0.8 \mathrm{~cm}$ to $12 \mathrm{~cm}$. However, $30 \%$ did not achieve a change and one man increased his waist circumference by $0.9 \mathrm{~cm}$.

Only around half of the sample completed both pre and post programme questionnaires regarding behaviour change. As such, the sample is limited to a cohort of 23 participants. Of these, the most successful behaviour change achieved was increased physical activity, whereby $70 \%$ increased the number of days they were physically active for more than 30 minutes. This was higher than the average for the overall Shape Up programme delivered in other setting, $64 \%$.

In terms of improving diet, $42 \%$ reported an increase in fruit and vegetables, higher than the broader programme average of 35\%; and 38\% reported that they consumed fewer foods that were high in fat and sugar, lower than the overall programme average of $40 \%$. Although the collection of data on long-term changes (i.e., six and twelve month questionnaires) was challenging with poor completion, the current results presented are encouraging.

The stadia based approach to promoting health with men appears favourable. This is supported by feedback from participants who suggested that men liked the stadium venue, being with like-minded people, a programme tailored to a male audience, excellent motivational support from the practitioners and the banter and camaraderie of the programme. Participants highlighted:

"As an Albion fan, I got to see bits of the stadium I wouldn't normally have seen, but more importantly than that, I found the advice given from the team was invaluable. The advice on food types, portions sizes, and what was actually in what I was eating, coupled with the workouts, saw the weight drop and the belly diminish..."

"I am now a confirmed label watcher looking for the right foods and salt content has become an obsession... I will miss it when we finish in a few weeks' time, hopefully some of the guys will continue the pod sessions... I have now rejoined my local gym to progress things further." 
In conclusion, this contribution offers an insight into a stadium based health promotion programme. The majority of men taking part in AITC Shape Up at the Stadium programme lost weight over period of the programme. This compared favourably with other Shape Up programmes delivered in the city, supporting the use of sports stadia for men. The programme successfully supported the majority of men to increase their physical activity levels, with less favourable, yet positive changes in diet. Supporting men to lose weight and maintain a healthy weight remains a challenge in the context of the obesogenic environments. In terms of men's health, football stadia present opportunities to engage a traditionally 'hard to reach' group to achieve successful outcomes.

Our next contribution is from Dr Andy Fuller. Andy researches sports and urban culture and edits the Reading Sideways website. In his contribution, Andy discusses his experiences and insight into health promotion through sports clubs from both top and lower leagues in The Netherlands, and introduces the concept of 'gezellig' as a typically Dutch way of fans being emotionally involved with their clubs.

\section{Gezellig Stadia: Observations from The Netherlands}

Football is an integral part of communal life in The Netherlands. The country has the world's highest participation rates in club football per capita (Kuper 2003). Although there are only four large stadia (i) Amsterdam Bijlmer Arena (on the southern fringe of Amsterdam and home to Ajax, (ii) de Kuip (in Rotterdam, home of Feyenoord), (iii) Philips Stadium (in Eindhoven, home of PSV), and (iv) Kyocera Stadium (in The Hague, home of ADO Den Haag), the Dutch landscape is marked by the rectangular shapes of football grounds and hockey grounds. These grounds are rarely open for the public and are often lined with fences and have locked gates. The grounds belong to 
football clubs, and if one wants to play, one must join a club, or be satisfied playing on half-sized grounds in improvised public spaces. The Netherlands has high population density, and land is at premium. Due to its low-lying geography the landscape needs to be managed, controlled intensely, which is reflected in the highly organised nature of the country's use of public and green space: the landscape needs to serve an environmental function as well as providing a communal, recreation space.

Members are loyal to and proud of their clubs: the clubs are integral to identity formation, which goes 'hand in hand with the production of difference, for each act of inclusion and identification is based on exclusion and the making of boundaries' (van Slobbe, Vermeulen, Koster 2013, p.1364). Many prefer watching their club's amateur teams play, rather than watching the professional Eredivisie and Jupiler Leagues. Dennis v. P., a member of Quick in The Hague says, 'the city is quite fragmented. The city's layout clearly structured and has clear classes. Most people are far more attached to their local club, where they play or serve as volunteers, rather than supporting the city's only professional team, ADO Den Haag. If you are not from that part of town, or don't have a family connection with the club, most people don't support it, just because they play in the Eredivisie (Interview, February 2016)

Bert V., a life-long member of Koninklijke HFC in Haarlem, reinforces this sense of attachment to local clubs, over the more nationally or internationally prominent clubs such as Ajax, Feyenoord or PSV. 'I have little interest in the Eredivisie. I have no time for watching Ajax or whoever. Sure, at the time of the World Cup, or if a Dutch team is playing in the Champions League, I will support them in a nominal manner, but it is not something I invest in emotionally. My club is Koninklijke HFC' (Interview January 2016). The highly valued quality of gezellig (a sense of warmth, cosiness, familiarity, belonging) is also reflected in the affection that members keep for their local 
club. Although the quality of gezellig generally applies to indoor spaces, the term has relevance to the feeling, atmosphere that can be generated at a football stadium.

Gezellig is the feeling of warmth that familiarity, comfort, order and security that is a result of physical conditions, personal interactions and pattern. As such, local amateur football clubs play an important role in communal life, maintaining social relations and fostering positive changes in living a healthy life.

The Netherlands has one of the most active populations in Europe. Sport is an important form of leisure activity for the Dutch: $52 \%$ of the population participate in sport on a weekly basis, well above the European Union average of $38 \%$. This participation, but also the sports infrastructure, for example, is determined in part by social developments in the Netherlands (Tiessen-Raaphoorst and Breedveld, 2007). Despite this, as in other parts of the world, fast (fried) food is very popular and is a part of Dutch lifestyle. Bitterbollen, croquettes, frikandel, patates frites are staple warm and savoury snacks eaten throughout the whole year. Fast food chains, has shops at train stations, main shopping streets, and also - unsurprisingly - at football stadia. Sweets such as oliebollen (deep-fried dough), stroopwafel (a waffel filled with a caramel syrup), poffertjes (small, spongy pancakes) are very popular; slaagroom (whipped cream) is offered with hot chocolates and cakes.

A healthy Dutch lifestyle seems to be characterised by eating in moderation (another important value), the use of bicycles as a main mode of transport (another important aspect to being Dutch) and being able to walk easily throughout the small city or town that one lives in. Being a member of a sports club - whether it be football, hockey or athletics - provides an important framework for structuring one's physical exercise. The clubs offer socialisation, communal engagement and friendships. Members are active as volunteers even if not always intensely active as players or 
participants. Being Dutch, or 'acting normal' (as people say) proves at times both an impediment and encouragement to living a healthy lifestyle: olibollen, for example, are an integral part of winter-time celebrations and festivities, just as one eats fries or croquettes (deep-fried bread-crumbed rolls, containing some kind of meat) while watching football.

I have been visiting football grounds and stadia in The Netherlands while living in Leiden 2014-16. The observations below are drawn from a range of stadium visits, mainly conducted while going to games and talking with various club volunteers and people, who have over time, become friends. The reflections below seek to explore the notions of healthy stadia against the sense and feelings of attending games and atmospheres created. That is, I explore to what degree is the stadium, or particular football club culture, indicative of healthy social relation conditions. In this regard I am asking whether the stadia facilitate positive health and social relations.

The Amsterdam Bijlmer Arena is the most modern stadium in The Netherlands. It has its own train station and is integrated into an entertainment precinct close to restaurants, bars, cinemas and concert venues. It is the home ground of The Netherlands' most successful club, Ajax, and is walking distance from the club's training venue at de Toekomst. Ajax left de Meer stadium (their home since 1934) in 1996 to move into the multi-purpose stadium. The shift in home stadium was common throughout the 1990s amongst the Eredivisie clubs, as clubs moved out of their outdated stadiums into newer, safer and more modern facilities (Spaaij 2007). The transition to a new stadium is always a tense affair: the memories, demands and wishes of supporters need to be taken into account in order for supporters to maintain a sense of identification with the club. Ajax has struggled hard to maintain a sense of the 'Ajax 
feeling' after moving in to the Amsterdam Arena (Oppenhuisen and van Zoonen 2006, p.65).

The Ajax Run of 25th October 2015 sought to increase community participation and identification with Ajax football club and to promote healthy living. This was the second year of holding the event, and, unlike the previous year, the race was followed by a live-screening of an away match (against Vitesse Arnhem). Coincidentally, it was the first Ajax game to be played after news broke of legendary player Johann Cruyff being diagnosed with lung cancer. The start line of the race was just outside of Amsterdam Arena and the finishing line was at the northern end of the pitch. The Ajax Run is an initiative of Ms.Eefje Schep, a press officer at Ajax, and her colleagues. I met her after the race, and we spoke during the half-time of the Vitesse-Ajax game. Eefje described the origins and purpose of the event as follows:

I love running myself, and a couple of years ago, some of us thought of holding this event. We wanted to attract more people to come to the stadium to see what it is like and also to hold an event that would involve a broader cross-section of the nearby community. Today, we had around 3,600 runners; last year, we had about 3,300 runners. So, it has been a success. Last year we organised the event in a weekend that Ajax played no game. This year we were also looking for a free weekend but it was unfortunately not possible to find a date on which the stadium was available and Ajax did not have to play a game. Now we decided to go for this date and to broadcast the game Vitesse versus Ajax after the run on a big screen in the stadium.

The participants were enthusiastic after the first event so, perhaps this is one reason for the greater number of participants for this second event. We sent out information to the media, the local athletics clubs and the local schools; we advertised it through our own website and social media channels. All the profits from the event go to the Foundation of Ajax and through this event we also want to promote a 'healthy lifestyle' amongst our community.

We had several different communities participating in this event. Including, Ajax fans who wanted to run on the pitch and watch the event; professional runners, people from the local community and runners who were participating in the event through their work. Some former Ajax players were running as well. Sjaak Swart and the Ajax players Thulani Serero and Arek Milik who were injured were present for the award ceremony of the winners. The atmosphere was great. 
I sat in the northern stand watching the end of the race. Runners, sometimes bedecked in Ajax jerseys, crossed the line often full of exuberance and with arms raised. Although the top three or so runners finished with times below 35minutes, the bulk of participants finished well above 40minutes, and many above 1hour. It was not an elite competition, but the point was participation and creating an incentive to run, exercise, set a goal for oneself. As Eefje states above, the atmosphere was indeed great. Participants had friends and family in the crowd and there was much cheering; the gestures of runners also indicated that they were satisfied with their achievement of either finishing or getting a personal best.

Johan, an Ajax fan, took his seat up in the stand, where he was greeted by his wife and teenage daughter. During the one-minute of applause for Cruyff - based on the recent news of his lung cancer diagnosis - Johan stopped our conversation in order to clap along with the rest of the crowd. Somewhat, ironically, Johan had a lit-up a cigarette only a moment earlier, in this rokvrij (smoke-free) stadium. Johan described the Amsterdam Arena as 'colder' than the previous stadiums he has watched Ajax play in de Meer and the Amsterdam Olympic Stadium. He says, those stadiums are 'warm' (i.e. gezellig), because they are the venues in which he has seen Ajax's great victories and triumphs. That the Amsterdam Arena is clearly a warmer, more-sheltered and more luxurious venue, yet it does not trump the memories of the victories at other stadiums;

I run perhaps once or twice a week. I am an Ajax fan, so, when there was this opportunity to run on this holy ground, of course I wanted to do it. I have also done the Amsterdam half-marathon, which starts and ends at the Amsterdam Olympic Stadium, another important stadium in Ajax's history. I am from Amsterdam; I was born here and my grandfather too, was born here. But, now, I live in Almere. For two seasons, I had membership tickets with Almere City FC, but my heart was always with Ajax. We moved to Almere because of my daughter. These days, things are different. If for example, children are mucking around and you tell them 'hey don't do that', they don't say, 'sorry sir, we won't do it again', like we used to in the past, they'll start shouting abuse and they 
probably have a knife. We moved to Almere where it is quieter and safer for my daughter.

Football fandom is an expression of identity, heritage and loyalty. Eefje sought to draw on the enthusiasm of Ajax fans for their club to get them involved in a healthy, sporting activity. For a fan such as Johan, finishing on the Ajax home pitch was an added incentive to link with his hobby for running. The Amsterdam Arena, though in the mind of Johan lacked the gezellig-ness of de Meer and the Olympic stadium.

My second insight relates to the Middelmors Sportpark of Rijnsburg, home to the Rijnsburgse Boys, which contrasts significantly with the highly-multi-functional Amsterdam ArenA. The Rijnsburgse Boys, founded in 1930, is a Topklasse team (thirddivision) from a village outside of Leiden and has around 2,000 members and about 50 different teams; most of which are youth teams. The club is a successful amateur club and has up-to-date facilities. Its home ground is used for an annual FIFPro tournament for un-contracted professional footballers. Crowds are generally around 1,000, but for bigger games (such as against local rivals Noordwijk) attendance can swell to around 2,000 . The ground is easily reached by foot, bicycle, bus, scooter or car. The bicycle racks are largely full during games; indicating not only the Dutch habit of cycling but also suggesting that many only make short distances.

The large yellow and black Rijnsburgse Boys flags in houses near the stadium also suggest a strong and proud support for the club. Atmosphere on game days is generally one of relaxed enthusiasm for watching a game of football coupled with bonhomie. I was introduced to Mr.Lennart Paauw, a board member of Rijnsburgse Boys, by Rijnsburgse Boys press officer, Mr.Henk Hogewoning. In discussing healthy stadia, we discussed the kinds of food available at the club and the challenges involved 
in making a shift from the traditional fast food to healthier alternatives. Lennart

explained Rijnsburgse Boys situation as follows:

Well, it is difficult. Eating fast food is a part of football culture. When people come to a game, they want to eat fast food. Perhaps, they eat well for five or six days a week, but, when they come here, they eat fast food. We recognise this, but we are doing our best to change it. Even if at the same time, we recognise that the change is going to be slow. It is very difficult to change culture. We have at the moment around 30-40 volunteers working today. We have a dozen or so working in the canteen. No-one gets paid. But, the good thing is, that we have volunteers who are very much behind promoting alternatives to fast food. At the least it is about making sure that there is whole-grain bread, that there is fruit available. Our staff do their bit to set a positive example to others: they themselves choose the healthy options. Slowly, over time, we can hopefully establish a culture that separates 'fast/junk food' from being at the football.

One of the hurdles is that providing fast food is much cheaper and easier than providing healthier food, which of course, perishes quicker and requires more people involved in its serving. So, although we value fresh and good food, it still has to be balanced against what we can afford in terms of costs, with what facilities we have available and what our customers - i.e. our members and players want. Our club is also open on Thursday nights, and it is clear that people eat and drink more healthily on Thursday nights. So, it seems that the weekend is a time where people eat in a less-disciplined manner. We can see by the levels of consumption that this is a clear pattern. We have a good atmosphere at our club. People don't drink too much; we don't serve alcohol by the side of the pitch. If people drink they do so before the game or afterwards in the social club. But, while watching the game, people aren't drinking or being abusive. It is a football crowd, so of course, there are moments of tension and excitement, but, generally, there is no trouble.

In conclusion, the entrenched culture of club football and loyalty in The Netherlands means that football clubs can play a vital role in developing healthy lifestyles. Whilst this commentary offers some observational and reflective insight, it is clear that clubs with huge supporter bases like Ajax of Amsterdam are able to draw on their brand-appeal to attract participants for events they would not otherwise attract. Similarly, smaller, more-locally based clubs such as the Topklasse club Rijnsburgse Boys are able to make incremental changes to the lifestyles of their community working in consultation with them and thanks to the support of (unpaid) volunteers. 
Football is an integral and all-encompassing aspect of Dutch culture that brings together many of the complexities of Dutch national-identity and tradition (van Hilvoorde, Vorstenbosch and Devisch, 2010). The healthy lifestyles of walking, cycling and playing regular sport are also countered by consumption of fast food, cigarettes and large quantities of beer, often while being a spectator at a local or Eredivisie football game. Gezellig stadia are those in which the fans, supporters and volunteers can both identify with as well as contribute to. As such, football clubs and their associated stadia are positioned to play a contributing role in promoting health in their local communities.

In our next contribution, Mr Clive Knight at Oswestry Team Tennis discusses a community based tennis facility that has also taken on a healthy stadia approach, something that will be echoed in some of the full articles later in this special edition. Clive offers his personal insight into how a club originally set up to deliver a single sport has now become a multi-activity deliverer within its community, thereby contributing to its member's health and wellbeing. The club has also encouraged additional sports activities to take place within the adjacent town centre park, and make better use of the existing facilities to increase levels of physical activity within the local population.

\section{Owestry Team Tennis}

Oswestry is a rural market town situated in Shropshire (England) with a population of around 40,000 including the immediate surrounding area. Oswestry Team Tennis (OTT) is a junior tennis club with two floodlit courts - one macadam court for the full game, one court for multi-activity, and four smaller orange/red courts designed specifically for children aged from 4 to 9 years, in order to progress through structured mini tennis activities, leading to the full game. OTT is based in Cae Glas Park in Oswestry which is 
a seven acre site adjacent to the Town centre, and regarded by the Town Council as Oswestry's "jewel in the crown". The club has a long lease with Oswestry Town Council to use the tennis courts. The public can make use of the facility when the club is not occupying them.

OTT informal activities started in the 1990's when coaching of promising local juniors started at a nearby secondary school. OTT became a Lawn Tennis Association (LTA) accredited club in 2002 to meet the increasing local demand to provide tennis opportunity for juniors of all abilities in the town. In 2005, Barclays Spaces for Sports invested $£ 100,000$ - a mixture of capital and revenue into the club to fund the new facilities in Cae Glas Park and provide a revenue stream to pump prime the club in its infancy. The club is one of 202 such Barclays Spaces for Sports facilities spread across the country. The club is run by volunteers and is a charity, which is unusual for tennis clubs, but it serves the purpose well

The club is one of 202 such Barclays Spaces for Sports facilities spread across the country. From an initial 50 members in 2002, the club now has over 200 junior members. The club provides coaching sessions throughout the week with development squads, and a full range of group sessions are on offer on Saturdays. Competition match plays are ran throughout the year for all groups from mini red through to LTA rated players including adults. Participants' motivations to attend include to exercise and consequently improve their health, to be with their friends, and to become the best they can be in that sport.

Thirty years ago, there was a very different attitude with "becoming the best you can be" being the major reason for taking part, and coaches generally only interested in players in this category. Encouragingly today, there is raised awareness that youngsters playing other sports is a good thing and will help develop their core skills, including the 
fitness and health agendas. OTT has a myriad of youngsters who play multi-sports and it takes great pride in its members succeeding in other sports. This holistic multi-sport approach to governance and operations has allowed OTT to look beyond its existing delivery to grow membership and participation within the club, whilst bringing it closer to the local community.

In the last few years, awareness has improved across the local community as to what a brilliant town park the tennis club operates within, and the need to deliver more structured physical activity opportunities, extending current provision in the park. Due to OTT now operating as more than just a tennis club, it has become increasingly obvious to the trustees that the club has a wider responsibility to the community than just the provision of tennis activity. Whilst its core activity is and always will be tennis delivery, the education of its overall membership and beyond to lead healthier and more social lives has become more important than just producing performance players (although this may also help produce better tennis players!).

By operating the OTT community stadia in true community fashion rather than in an isolated and protective manner, the clubs relationship with the Town Council has grown positively. Following the success of the Olympics and Paralympics in 2012, OTT was entrusted by the Town Council in 2013 to take over the whole park to deliver a pilot Oswestry Community Games to gauge interest in bringing local sports organisations from their isolated venues into a central venue to work together to deliver a fun activity day, and this worked very well on the day. The focus of these Games is very much on encouraging people whatever their age or ability to do more physically, improve their health, and the inclusion agenda is a vital ingredient to increasing participation. 
Following its success in 2013 , this is now a recognised annual event in Oswestry's park calendar and has grown to include our local arts organisations. Participation on the day has also grown from 500 to around 1000 people in 2015 with almost 40 local organisations coming together to deliver the Games. Organisations benefit from taking part by showing what their club offers to potential users, sharing good practice, working together, recruiting new members and having fun.

The spin off to OTT is that apart from the success of working with many sports and arts organisations from the local community and seeing the park used to its full effect, this event and our role within it support recruitment of new members. Using the park in this way has also encouraged other organisations to make use of it in a similar way.

My concluding thoughts would be to advise community stadia managers and practitioners to look at what your facility and its surrounding amenity area have to offer, work collaboratively (including other sports), and support broader community events that engage with your local community, all of which will help contribute to greater awareness of and participation in your site and provision.

Over the last decade changes in the media landscape have given rise to new opportunities for community sport providers to market themselves at no cost. Here $\mathrm{Mr}$ Simon Lansley, of ConnectSport, offers an insight into how they can capitalise to share their work and help communicate the social value of their work.

\section{Sharing the community sport message}

Traditionally the mainstream media has always relied on elite sport to satisfy their audience and drive newspaper sales or website visits. This has created the belief amongst those delivering at community or grassroots level that there is not much 
interest in their work amongst the general public, even when there may been tangible public health outcomes. Subsequently with tight budgets focused on delivery, little or no attention is paid to marketing. In this short perspective, I hope to demonstrate the potential of bringing your programmes, your story and your impact to social media. This is particularly important for those working in or towards the healthy stadia agenda and are aiming to share their progress, impact or influence policy.

For many reasons the 'sport for development' sector is emerging from the shadows, as recognised by the UK Government's recent sports strategy which applauds the work of organisations which are 'outside' sport but using sport to benefit society. I worked for one of those, Street League (a major national football based education and employment charity), for four years and witnessed first-hand the stories that are being told and the value they provide for local media. Before Street League, I also spent 15 years in the mainstream media at the UK's national news agency, The Press Association. It was a special place to work because journalistic principles, such as objectivity and the right to reply, were sacrosanct. More and more, however, it seems that in certain areas of newspaper industry, profit and loss has come to cloud editorial decision-making.

So when it comes to redressing the balance, thank goodness for social media, which has enabled community and grassroots sports providers to find and speak directly to their own audiences. For those working on, and towards, public health outcomes whether from sports stadia or from a community or grassroots sport organisation, the message is simple. Sign up for free and get tweeting; stick to your key messages but be friendly, be conversational and eventually your audience - the people who care about, or benefit from what you're doing - will gravitate towards you. Most importantly, those people who follow you are your advocates. In other words, the people who will market 
your organisation for free. This, in turn, has got even the most media-shy grassroots sport organisations thinking about how they appear to the wider world. If social media is your shop window, make sure you're selling yourself when potential customers happen to pass by. Whether it's the key messages on your website or what you're tweeting, a new funder could be checking you out at any time, while local journalists with an agenda are almost certainly scouring social media looking for someone who fits the bill.

Social media offers avenue to share your progress, your developments and your impact. If you can get your brand assets right online and this will also breed confidence amongst your delivery staff. It's almost certain that, thanks to the benefit you are bringing to the local community, they are proud to work for you and eager to 'walk the brand'. Involve them in the creation of your key messages, and encourage them to connect (online and offline) and build relationships with local journalists. Make sure they keep it short, sweet and to the point - too much jargon or detail will lose people's attention - and remember what you're selling needs to be of value to the media outlet's audience. Can your stadia provide an accessible space and place for local services? Can your programme help to solve a problem directly affecting the listeners of your local radio station? Provide case studies of real people, showing real impact in the community. We know from recent sport policy that evidencing social value is key. More than anything, remember you are having a real impact on society. So make sure you let people know.

Finally, we are pleased to receive and include a contribution from Mr Daniel Cade of Schwery Consulting. Daniel offers an insight into the challenges facing governing bodies of sport, mega events and sports venues themselves when considering the wider sustainability of sponsorship agreements, something that in addition to 
environmental and economic considerations, also includes social consideration such as health and wellbeing. Daniel will draw upon a number of examples, challenges and considerations when discussing the complex relationship between sport, sponsorship and sustainability (including health and wellbeing).

\section{Sustainable Sponsorship}

The London Organising Committee of the Olympic and Paralympic Games (LOCOG) demonstrated sponsorship's true potential when it created an additional marketing rights designation for sustainability partners. It formed a working group among marketing partners with the aim to reach more people and inspire a step change in sustainable living. This move took LOCOG into unchartered territories for a major sport event organiser and should have paved the way for others to place sustainability issues on a higher footing. Indeed, as many would have hoped for sustainability to be considered in cooperation with sponsorship partners (London 2012, 2011).

LOCOG offered each sustainability partner the opportunity to develop its own sustainability project for London 2012, in addition to assisting with the sustainability objectives of the organising committee. BMW, for instance, through its role as 'Automotive Partner', wanted to increase public awareness of the most advanced fuel and $\mathrm{CO}^{2}$ saving technologies. British Petroleum (BP) was the official 'Carbon Offset Partner' for the Games and was committed to offsetting all the $\mathrm{CO}^{2}$ emissions for the 'Games Family Transport Service', as well as launching a spectator and partner activation programme and young leaders programme.

Traditional sponsorship practice is under increased scrutiny. As such, LOCOG's approach, which followed and built on that of its predecessor VANOC (Vancouver Organising Committee for the 2010 Olympic and Paralympic Winter Games), should 
have been among a group of good practices that triggered a renewed commitment to meaningful sponsorship deals within the sport industry that are more in tune with the times. However, there has yet to be credible progress on LOCOG's initiative in the three and a half years since London 2012. Looking ahead, the Rio 2016 Sustainability Report (published in September 2014), which reports on "detailed operational planning and pre-Games operations", highlights an acceptance of its potential influential role in raising awareness of sustainable lifestyle choices among spectators, sponsors and partners (Rio 2016, 2014). The report goes on to identify sponsors as one of 12 key stakeholders, which it has engaged with "in discussions [...] on partnerships to support [it's] sustainability objectives." However, it did not explain any tangible outcomes of these discussions (Rio 2016, 2014).

Debates surrounding the ethics of corporate sponsorship of sport and other cultural events will continue, especially surrounding companies that sell, or have sold, products that are deemed hazardous to the health of consumers and society in general. Indeed, for the London 2012 Olympics, controversy surrounded Dow Chemical, BP and Rio Tinto's partnerships due, as one campaigner put it, to the devastation these companies have caused to communities around the world. Moreover, Coca-Cola and McDonalds have resulted in criticism as sponsors due to their association and potential contribution to existing public health issues, such as obesity and diabetes, which currently plague the UK and beyond. This contribution rather focuses its attention on the practice of sustainable sponsorship. It highlights some of the challenges that other major events may have encountered in an attempt to 'clear the way' for future event organisers to continue to experiment and innovate within this field for the benefit of sponsors, organisers, and society (GreenNet 2016). 
Traditional sponsorship practice, that associates a brand to a particular property or event, can amass goodwill through brand association among a target population. However, it does not address this author's perception of high levels of animosity that currently perceived, developed and delivered towards the corporate sector, and may even serve to aggravate the situation. In an effort to regain trust, a more hands-on approach, as demonstrated by LOCOG and its sponsors, can enable other sponsors and sport organisations to communicate a long-term commitment to responsible business practice to a broader target audience. This practice can be termed sustainable sponsorship. Sustainable sponsorship in sport can be defined as the sponsorship of a sport property or event whereby both parties are responsible for a long-term positive impact on society or the environment. Sustainable sponsorship can be more effective, and believable, if it is used as an expression of a long-standing commitment to corporate social responsibility (CSR) or sustainability (both terms, CSR and sustainability are used interchangeably in this section).

Establishing a sustainable sponsorship agreement without a firm CSR grounding is pointless. Social media has seen to it that customers and the general public are wellinformed and can see through organisations making ambiguous claims. However, implemented under the right circumstances, sustainable sponsorship can be used as an effective means to communicate to a number of stakeholders (current and future employees, public authorities, pressure groups), helping to maximise opportunities and minimise risks. It appears important to consider the potential of operations aligned with such an approach. Indeed, many large corporate entities have now developed sound CSR practices that make up part of their DNA. Coca-Cola, for instance, has been very public about its intentions to become water-neutral by 2020. Since 2004, Coca-Cola has 
replenished an estimated 153.6 billion litres of water back to communities and nature through 209 community water projects in 61 countries (Coca-Cola 2015).

Sport organisations are intrinsically different to companies in other industries, yet their motivation for implementing a social responsibility strategy is not. Sport's unique influence on society has helped to guide some sport organisations to identify areas in which they can harness their sport's positive values to benefit communities. For example, UEFA works with selected partners across Europe to address social issues connected to football. Since 2008 it has supported, promoted and reported on several social responsibility projects, under the umbrella slogan of 'Respect', during its EURO tournaments (UEFA 2013). However, collaboration between corporate sponsors and sport organisations on projects that create a sustainable impact on society have so far been lacking. And, until now, issues regarding the alignment of different CSR strategies have perhaps justified the relative inaction. These issues are outlined below.

Since CSR focus areas and implementation methods will vary from one organisation to the next, logic tells us that sustainable sponsorship should not be a 'one size fits all' approach. In a different approach to Coca-Cola, Nike's environmental CSR goals focus on producing environmentally friendly products. One of the initiatives it has developed is the Nike Considered Index. It uses this to rate the ecological footprint of the products that it manufactures. A Considered product is one that has been made with the fewest possible materials and can be easily recycled into a new product or "safely returned to nature" at the end of its life (Nike 2015). These companies' choices will define their overall strategy, influencing day-to-day decisions, like sponsorship. Rather than making ad-hoc charitable donations, they will support meaningful projects that meet specific business goals and stakeholder expectations. Sustainable sponsorship practitioners would need to align the CSR commitments of different organisations to enable them to support a shared, or unified, social goal.

Appearing to have good intentions does not necessarily mean that you are 'doing good'. This is one of the most widely used, and necessary, CSR industry clichés. To increase the chances of having a positive impact, and not causing harm, good things must be done well. A responsible 'do no harm' approach can only be validated by the use of an impact assessment. Both UEFA and Nike have policies that dictate the use of external evaluations to assess the social impact of projects that they support. In relation to sustainable sponsorship initiatives, this means that projects should not be designed only for their alignment with supporting partners but, primarily, because they help to combat a problem affecting society. Selecting a suitable project 
should be a bottom-up process that starts by assessing the potential impact of the project on its stakeholders and then looks for the alignments among partners' CSR strategies. This added variable makes the task appear slightly more tedious.

Time pressures raise the challenge of alignment if the objective is to create sustainable sponsorship agreements for a one-off event. Until LOCOG, the prospect of involving so many partners (host countries and cities, local implementing organisations, sponsors, sport federations and associations) in sustainable sponsorship project negotiations has been a deterrent, although that is not to say it has not happened on a smaller scale. The practice of effective time management is necessary to ensure that, instead of being a hindrance to progress, multi-sector partnerships are nurtured to create synergies that mobilise the skills and resources of each partner group. The potential to strengthen the impact of a project and meet the needs of all partners and stakeholders is great.

To conclude, there should be little doubt that the sponsorship industry will adapt to changing times and find the necessary solutions to sustainable sponsorship. One of which might be to empower local non-governmental organisations to determine the alignments. Given the time and funding to investigate the partners' expectations, these organisations are best placed to come up with an idea that suits everyone. Their knowledge and awareness of the issues affecting society should allow them to provide relevant and viable options to the other partners. In this new era when the 'large and global' will be judged more and more by how they treat the 'small and local', continuing on the traditional sport sponsorship path is simply not enough. It is in the best interests of the parties involved in agreements to overcome the challenges and adopt a sustainable sponsorship approach, for their own economic benefit and for the benefit of society.

\section{Concluding comments}

The contributions presented within this applied article offer a range of perspectives from those involved in the healthy stadia agenda. Considerations from international, national and local perspectives, including operations and interventions in professional sport clubs and grassroots or community settings have been presented. These 
contributions support the notion that the healthy stadia, whilst an established applied concept, is a growing research area. Moreover, a range of perspectives on the need to raise communication of the healthy stadia agenda across various media have been discussed. We hope this insight establishes further interest, discussion and research on, and around, the healthy stadia agenda. Furthermore, we hope that this insight acts as a catalyst to strengthen the dialogue and partnerships between researchers and applied practitioners.

\section{References}

Bangsbo, J., P. Krustrup, and J. Dvorak. 2014. "Special Issue: Football for Health Prevention and Treatment of Non-communicable Diseases across the Lifespan through Football.” Scandinavian Journal of Medicine \& Science in Sport 24 (S1): 1-150.

Coca-Cola. 2015. "Coca-Cola on Track to Meet 100\% Water Replenishment Goal" Coca-Cola, August 25. Accessed 7 January 2016. http://www.cocacolacompany.com/press-center/press-releases/coca-cola-on-track-to-meet-100water-replenishment-goal/

Curran, K.,, B. Drust, and D. Richardson. 2014. "'I just want to watch the match': a practitioner's reflective account of men's health themed match day events at an English Premier League football club." Soccer \& Society no. 15 (6):919-933.

Drygas, W., J. Ruszkowska, M. Philpott, O. BjÖrkstrÖm, M. Parker, R. Ireland, and M. Tenconi. 2013. "Good Practices and Health Policy Analysis in European Sports Stadia: Results from the "Healthy Stadia" Project." Health Promotion International 28 (2):157-65.

EURO 2016. 2015. "Social Responsibility \& Sustainability - One-year-to-go report, 2015" UEFA. Accessed 7 January 2016. http://www.uefa.org/MultimediaFiles/Download/uefaorg/General/02/26/41/78/2 264178_DOWNLOAD.pdf

GreenNet. 2016. "World's worst polluters sponsor 'greenest' Olympics." GreenNet. Accessed 7 January 2016. https://www.gn.apc.org/network/news/worlds-worstpolluters-sponsor-greenest-olympics

Hunt, K.,, S.Wyke, C. M. Gray, A. S. Anderson, A. Brady, C. Bunn, P.T. Donnan. 2014. "A Gender-Sensitised Weight Loss and Healthy Living Programme for Overweight and Obese Men Delivered by Scottish Premier League Football Clubs (Ffit): A Pragmatic Randomised Controlled Trial." The Lancet 383 (9924): 1211-21. doi: 10.1016/S0140-6736(13)62420-4.

Kuper, S. Ajax, The Dutch, The War, London: Orion, 2003. 
London 2012. 2011. “A Blueprint for Change.” London 2012, April. Accessed 7 January 2016. http://learninglegacy.independent.gov.uk/documents/pdfs/sustainability/2london-2012-sustainability-report-a-blueprint-for-change.pdf

Martin, A., S. Morgan, D. Parnell, M. Philpott, A. Pringle, M. Rigby, A. Taylor, and J. Topham. 2016. "Editorial: A Perspective from Key Stakeholders on Football and Health Improvement.” Soccer \& Society 17(2): 175-182.

Oppenhuisen J. and L. van Zoonen. 2006. "Supporters or Customers? Fandom, Marketing and the Political Economy of Dutch Football." Soccer and Society 7 (1): 62-75.

Nike. 2015. "Produce Design - Considered Design Index" Nike. Accessed 7 January 2016. http://www.nikebiz.com/crreport/content/environment/4-1-1-productdesign.php?cat=product-design

Parnell, D., and D. Richardson. 2014. "Introduction.” Soccer and Society 15 (6): 823 827.

Parnell, D. and A. Pringle,(2016), 'Football and Health Improvement: An Emerging Field', Soccer and Society 17 (2): 171-174.

Rio 2016. 2014. "Embracing Change - Rio 2016 Sustainability Report." Rio 2016, September. $\quad$ Accessed 7 January 2016. http://www.rio2016.com/sites/default/files/parceiros/rio_2016_sustainability_re port_sept2014.pdf

Schwery Consulting. 2008. "UEFA EURO 2008 - Football \& Social Responsibility Evaluation Report” UEFA, October. Accessed 7 January 2016. http://www.uefa.com/multimediafiles/download/uefa/keytopics/82/57/46/82574 6_download.pdf

Spaaij,.R. 2007. "Football Hooliganism in the Netherlands: Patterns of Continuity and Change." Soccer and Society 8 (2-3): 316-334

Thielman, S. 2012. "McDonald's Deal Makes Health Advocates Sick - The controversy behind junk food brands sponsoring the Olympics" Adweek, August 6. Accessed 7 January 2016. http://www.adweek.com/news/advertising-branding/mcdonaldsdeal-makes-health-advocates-sick-142504

Tiessen-Raaphoorst, A. and K. Breedveld, 2007. Sport in The Netherlands: A Short Introduction, The Hague: Social and Cultural Planning Office..

UEFA. 2013. "Social Responsibility Report - UEFA EURO 2012 Creating History Together" UEFA. Accessed 7 January 2016. http://www.uefa.com/MultimediaFiles/Download/uefaorg/General/02/10/87/62/ 2108762_DOWNLOAD.pdf

van Hilvoorde, I., J. Vorstenbosch, and I. Devisch. 2010. "Philosophy of Sport in Belgium and the Netherlands: History and Characteristics." Journal of the Philosophy of Sport 37 (22): 225-236. 
van Slobbe, M., J. Vermeulen, and K. Martijn. 2013. "The making of an ethnically diverse management: contested cultural meanings in a Dutch amateur football club." Sport in Society 16 (10): 1360-1374. 